\title{
Origin and evolution of antibiotic resistance: the common mechanisms of emergence and spread in water bodies
}

\author{
Agnese Lupo $^{1 *}$, Sébastien Coyne ${ }^{2}$ and Thomas Ulrich Berendonk ${ }^{1}$ \\ 1 Institute of Hydrobiology, Department of Hydrosciences, Technical University Dresden, Dresden, Germany \\ ${ }^{2}$ Department of Biomolecular Chemistry, Leibniz Institute for Natural Product Research and Infection Biology - Hans Knöll Institute, Jena, Germany
}

\section{Edited by:}

Stefania Stefani, University of

Catania, Italy

Reviewed by:

Fernando Baquero, Ramón y Cajal Institute for Health Research, Spain

Manuela Coci, National Research

Council, Italy

*Correspondence:

Agnese Lupo, Institute of

Hydrobiology, Department of

Hydrosciences, Technical University

Dresden, Zellescher Weg 40, 01217

Dresden, Germany.

e-mail: agnese.lupo@tu-dresden.de
The environment, and especially freshwater, constitutes a reactor where the evolution and the rise of new resistances occur. In water bodies such as waste water effluents, lakes, and rivers or streams, bacteria from different sources, e.g., urban, industrial, and agricultural waste, probably selected by intensive antibiotic usage, are collected and mixed with environmental species. This may cause two effects on the development of antibiotic resistances: first, the contamination of water by antibiotics or other pollutants lead to the rise of resistances due to selection processes, for instance, of strains over-expressing broad range defensive mechanisms, such as efflux pumps. Second, since environmental species are provided with intrinsic antibiotic resistance mechanisms, the mixture with allochthonous species is likely to cause genetic exchange. In this context, the role of phages and integrons for the spread of resistance mechanisms appears significant. Allochthonous species could acquire new resistances from environmental donors and introduce the newly acquired resistance mechanisms into the clinics. This is illustrated by clinically relevant resistance mechanisms, such as the fluoroquinolones resistance genes qnr. Freshwater appears to play an important role in the emergence and in the spread of antibiotic resistances, highlighting the necessity for strategies of water quality improvement. We assume that further knowledge is needed to better understand the role of the environment as reservoir of antibiotic resistances and to elucidate the link between environmental pollution by anthropogenic pressures and emergence of antibiotic resistances. Only an integrated vision of these two aspects can provide elements to assess the risk of spread of antibiotic resistances via water bodies and suggest, in this context, solutions for this urgent health issue.

Keywords: water, freshwater, antibiotic resistance, environment, gene transfer

\section{INTRODUCTION}

Evolution of bacterial antibiotic resistances, and its spread and emergence, represent one of the most threatening health care problems with worldwide proportions (Hawkey, 2008). The rise of new resistances and of multi-drug resistances urgently asks for a better understanding of the factors and hot spots involved in its diffusion and development. All the known antibiotic resistance mechanisms, acquired by opportunistic and pathogenic bacteria, evolve by means of Darwinian forces, i.e., mutations occurring in pre-existing genes of the bacterial chromosome positively selected by environmental forces (Gullberg et al., 2011; Zhang et al., 2011). Mutations within the chromosome can be responsible for the decreased affinity of antibiotics to their targets. Furthermore, some resistance mechanisms (e.g., efflux pumps, chromosomal AmpC $\beta$-lactamases) are finely regulated in their expression and at a basal level confer a naturally reduced susceptibility to the drugs. Mutations in the genomic architectures regulating such mechanisms result in their over-expression and high level of antibiotic resistance (Jacoby, 2009; Coyne et al., 2011). However, adaptation to the selective pressure of antibiotics accelerates acquisition of antibiotic resistance genes by lateral transfer from donor species (Wiedenbeck and Cohan, 2011).
Aminov (2011) has reviewed the role of horizontal gene transfer mechanisms in environmental microbiota. Although many more studies are necessary to completely understand the role of horizontal gene transfer in the environment, experimental evidences have demonstrated that transduction has an important role in genetic exchanges among environmental microbiota, especially in freshwater. Horizontal gene transfer events are responsible for the acquisition of heterologous resistance mechanisms among species and from antibiotic producers to commensal and pathogen bacteria. Hospitals, human community, farms, aquacultures, and agriculture are reactors where the usage of antibiotics selects for resistant bacteria and promotes the gene exchange. Recently, much more attention has focused on the role of the environment and of connected ecological habitats, water bodies such as rivers, streams, waste water effluents, and lakes, that have been suggested to be important in facilitating the transport and transfer of the antibiotic resistance genes (Aminov and Mackie, 2007; Baquero et al., 2008). Low-cost pharmaceuticals, preventative medication with broad spectrum antibiotics together with the overuse of those drugs contribute significantly to the emergence of bacterial drug resistances (Depledge, 2011). The combination of all these factors together with an inadequate waste-management 
of the pharmaceuticals seem to be responsible for the alarming pollution of the environmental habitats such as agricultural soils and rivers, which probably contribute to the selection of antibiotic resistant bacteria and speed up the emergence of new resistances. Furthermore, rivers often receive bacteria from different sources, e.g., waste water treatment plants or water originating from urban effluent, industrial, or agricultural activities, thus constituting potential compartments where environmental, human, and/or animal related bacteria can coexist, at least temporally (Baquero et al., 2008). This mixing can result in two main risks: (i) many environmental bacterial species are provided with intrinsic antibiotic resistance genes, constituting part of the so-called resistome. These bacteria represent a reservoir of drug resistance mechanisms and may act as donors for human related bacteria which, in turn, could introduce new acquired resistance mechanisms in the clinics (Wright, 2010); (ii) due to the intensive usage of antibiotics in medicine, agriculture, and aquaculture, human or animal related bacteria are more likely to be selected for antibiotic resistances within polluted environments directly by the presence of antibiotics and indirectly through co-selection by other pollutants (Martinez, 2009). Thus, when antibiotic resistant bacteria contaminate rivers, their resistance mechanisms can spread in the environment through bacteria, and/or mobile genetic elements. The localization of antibiotic resistance genes on diverse genetic structures such as integrons, which are platforms for gene aggregation, and mobile genetic elements (e.g., transposons and plasmids), together with the presence of phages, enhance their spread, influencing the course of their evolution (Wright et al., 2008). In particular, integrons are supposed to have a crucial role in the development of multi-drug resistances (Cambray et al., 2010). Recent studies suggest that the spread of resistant bacteria in natural fresh water systems can reach drinking water supplies and thus enter the human food chain (Walsh et al., 2011). These factors lead to an unlimited spread of antibiotic resistances and indicate that water sanitation or a better management of the respective water quality is crucial for a better control of the spread of antibiotic resistances.

This review aims to describe the current knowledge on the origins of antibiotic resistances mechanisms and environmental reservoirs of antibiotic resistances. Mechanisms, originating and spreading in bacterial populations naturally occurring in the water habitats, will be highlighted. The consequences of horizontal gene transfer by transduction and gene recombination events mediated by integrons in water habitats will be underlined. The Table 1 summarizes the mechanisms of resistances cited in the review.

\section{MUTATIONS AND THE RISE OF ANTIBIOTIC RESISTANCES IN FRESH WATER HABITATS}

Mutations in environmental habitats occur frequently and usually depend on evolutionary or demographic factors such as population size etc. Generally, the rate of mutations can be increased due to anthropogenic impacts. However, especially antibiotics in the environment are more likely to select for specific mutations within bacteria. We summarize which mutations are most relevant in the context of antibiotic resistance in water habitats and might therefore be selected to a higher frequency due to the presence of antibiotics in water bodies.
In the clinics it has often been observed that the onset of spontaneous mutations in chromosomal bacterial genes may lead to the emergence of resistances affecting from one antibiotic to several drug classes of antibiotics. For instance, different point mutations in ribosomal proteins confer aminoglycosides, tetracyclines, and macrolides resistance; or in the RNA polymerase confer rifampicin resistance. To the best of our knowledge, these mechanisms have never been reported in bacteria of environmental origin, most likely because they have been overlooked.

Mutations in the penicillin binding proteins (PBPs) can lead to a decreased affinity for $\beta$-lactams drugs establishing bacterial resistance (Lambert, 2005). This mechanism has been extensively reported from clinical species. Although no direct reports exist from environmental sources, bacterial species such as Enterococcus faecium and Proteus mirabilis have been described to resist to $\beta$-lactams by mutations in PBP5 and PBP2 respectively. E. faecium has been frequently reported as contaminant of water body and $P$. mirabilis has been described as shuttle species between human or animal guts and water bodies (Sosa et al., 2006). The risk associated with the spread of organisms harboring such mechanisms is probably low. However, investigations to understand the link between PBP modification and fitness in terms of survival in water could yield significant information, to better assess the risk of spread for these species and antibiotic resistances. Probably, the role of mutations in the propagation and emergence of antibiotic resistant bacteria is minor compared to the acquisition of heterologous determinants. However, it seems that also very low concentrations of antibiotics can select for less susceptible bacteria (Gullberg et al., 2011). In environmental habitats this could result in an ecological imbalance with a higher prevalence of resistant microorganisms.

\section{CHROMOSOMALLY ENCODED CEPHALOSPORINASE}

Bacteria, especially Gram-negative, can also resist to $\beta$-lactams by the production of hydrolytic enzymes, $\beta$-lactamases. Detection of antibiotic resistant bacteria, in freshwater, harboring $\beta$ lactamases has been reported from several geographical areas. Clinical occurrence of $\beta$-lactamases encoding genes has been extensively reviewed (Bonnet, 2004; Pitout et al., 2005; Coque et al., 2008; Bush, 2010) and recently much attention to their propagation in the environment has been paid (see hereafter the section on acquired $\beta$-lactamases). According to Ambler (1980) $\beta$-lactamases are classified in four classes, simplistically ranging from A to D. Bush and Jacoby have proposed a categorization of the $\beta$-lactamases according to their hydrolytic and inhibitory profiles. For an exhaustive knowledge of $\beta$-lactamases nomenclature and biochemical characteristics, we suggest the recent review by Bush and Fisher (2011). Jacoby (2009) has reviewed the distribution, origins, and enzymatic action of AmpC $\beta$-lactamases, belonging to the class $\mathrm{C}$. The author has observed that $a m p C$ genes are located on the chromosome of bacteria belonging to different and phylogenetically distant species. ampC genes are widely distributed in bacterial species of environmental origins. Water borne species such as Aeromonas spp., Pseudomonas aeruginosa, Pseudomonas fluorescens, Ochrobactrum anthropi, as well as several Enterobacteriaceae, commonly found in water habitats, like Enterobacter spp., Morganella morganii, and Hafnia alvei harbor chromosomal ampC genes. Typically, ampC genes are regulated 
Table 1 | Overview of some mechanisms of bacterial antibiotic resistances occurring in water habitats.

\begin{tabular}{|c|c|c|c|}
\hline Antibiotic & Resistance mechanism & Host & Source \\
\hline \multirow[t]{12}{*}{$\beta$-Lactams } & PBP2 mutations & Proteus mirabilis & $-^{a}$ \\
\hline & PBP5 mutations & Enterococcus faecium & $-^{a}$ \\
\hline & ampC regulators mutations & Gram-negative species & $-a^{a}$ \\
\hline & ampC promoter region mutations & Escherichia coli & Recreational beaches, drinking water \\
\hline & Acquired AmpC & E. coli & $\begin{array}{l}\text { Recreational beaches, drinking water, river, } \\
\text { biofilm of water supplies }\end{array}$ \\
\hline & Acquired CTX-M & E. coli & River, sediment, birds \\
\hline & Acquired KPC & Klebsiella pneumoniae & Hospital waste water effluent \\
\hline & Acquired VIM & $\begin{array}{l}\text { Brevundimonas diminuta, Rhizobium } \\
\text { radiobacter, Pseudomonas monteilii, } \\
\text { Pseudomonas aeruginosa, Ochrobactrum } \\
\text { anthropi, Enterobacter ludwigii, } \\
\text { Pseudomonas pseudoalcaligenes }\end{array}$ & Hospital waste water effluent \\
\hline & Acquired IMP & Pseudomonas fluorescens & Waste water \\
\hline & Acquired OXA-23 & Acinetobacter baumannii & River, hospital waste water effluent \\
\hline & Acquired OXA-48 & Serratia marcescens & River \\
\hline & Acquired NDM-1 & $\begin{array}{l}\text { P. aeruginosa, Achromobacter spp., } \\
\text { Kingella denitrificans }\end{array}$ & Tap water \\
\hline \multirow[t]{8}{*}{ Fluoroquinolones } & $\begin{array}{l}\text { QRDR (quinolones resistance } \\
\text { determining region) mutations }\end{array}$ & $P$. aeruginosa & Hospital and urban waste water effluent \\
\hline & & Aeromonas spp., E. coli & River and lake, urban effluent \\
\hline & QnrS & Aeromonas allosaccarophila & Lake \\
\hline & & E. coli & River \\
\hline & QnrS2 & Aeromonas punctata, Aeromonas media & Lake \\
\hline & OnrVC4 & A. punctata & Waste water effluent \\
\hline & QepA efflux & Metagenome & River sediment, water from farm environment \\
\hline & OqxAB efflux & E. coli & Farm water \\
\hline Vancomycin & modification of the peptidoglycan & Enterococci spp. & Waste water effluents, biofilm \\
\hline $\begin{array}{l}\text { Chloramphenicol } \\
\text { and florfenicol }\end{array}$ & FloR efflux & $\begin{array}{l}\text { Gram-negative species Aeromonas } \\
\text { bestiarium }\end{array}$ & Aquacultures streams \\
\hline Tetracyclines & Tet efflux & Several species & Farms, sediment \\
\hline $\mathrm{MDR}^{\mathrm{b}}$ & Over-expression of RND efflux pumps & Gram-negative & $-{ }^{a}$ \\
\hline
\end{tabular}

${ }^{a}$ Observed in clinics but likely occurring in environmental and water habitats.

${ }^{b} \mathrm{MDR}$, multi-drug resistance.

and their expression is induced in the presence of $\beta$-lactams. The regulation of ampC expression is quite complex and has been reviewed for $P$. aeruginosa by Lister et al. (2009). Mutations in the transcription factor AmpR, a LysR-type transcriptional regulator, in the inner membrane permease AmpG, or in the cytosolic amidase AmpD, have been found to confer a constitutive expression of the cephalosporinase gene, even in the absence of antibiotics.

Mataseje et al. (2009) described the over-expression of ampC, by mutations in the promoter region, in Escherichia coli strains isolated from recreational beaches and drinking water (Table 1). As for other $\beta$-lactamases, chromosomal cephalosporinases have been described to evolve by point mutation, hydrolyzing a broader spectrum of $\beta$-lactams (Jacoby, 2009). Of particular concern is the plasmidic location of several $a m p C$ genes, which likely originated from the chromosomal cephalosporinase of environmental species. Details will be discussed in the section on acquired $\beta$-lactamases. AmpC enzymes are indistinguishable from the Dpeptidases, involved in the cell wall biosynthesis (Jacoby, 2009).
Thus, these enzymes probably adapted to confer $\beta$-lactams resistance from the natural physiological function, likely by gene duplication and mutation events (Sandegren and Andersson, 2009). Genes encoding AmpC enzymes are largely distributed on the chromosomes of many bacterial species of environmental origins. The intrinsic function of AmpC remains unknown, but the conservation of this enzyme in several unrelated species and the complex regulation of its structural gene highly suggests a physiological role. Deciphering this role could provide useful information on the evolutionary processes and driving forces that have lead to the selection of $\beta$-lactamases.

\section{DNA GYRASE AND TOPO-ISOMERASE}

Generally, mutations in the quinolone resistance determining region (QRDR) of $g y r \mathrm{~A}, g y r \mathrm{~B}$, parC, and parE genes coding for the bacterial DNA gyrase and the topo-isomerase IV respectively, are responsible for the onset of bacterial resistance to fluoroquinolones. This mechanism is known to occur in water 
environments. Schwartz et al. (2006) have detected ciprofloxacin resistant $P$. aeruginosa in six different treatment plants from four cities in Germany receiving the waste water from hospitals and cities. Molecular investigations demonstrated the occurrence of mutations in gyrA and parC genes. Further, the study demonstrated the spread of the ciprofloxacin resistant $P$. aeruginosa also in the waste water receiving river (Table 1). Alcaide et al. (2010) have reported about the gyr A and parC mutation conferring fluoroquinolones resistances in a variety of Aeromonas spp. isolated from freshwater. The authors found that the mutations in gyr A and $\operatorname{par} \mathrm{C}$, which are responsible for fluoroquinolones resistance, in recently described Aeromonas spp. such as Aeromonas media, Aeromonas veronii, and Aeromonas popoffi are similar to the one described in Aeromonas hydrophila, Aeromonas sobria, Aeromonas caviae, and Aeromonas salmonicida. In Portugal, Figueira et al. (2011) reported about mutations in gyrA and parC mostly linked to Aeromonas punctata and A. media isolated from an urban effluent. The same authors have recently characterized E. coli strains, isolated from a waste water effluent, that harbored mutations in gyrA and parC genes, likely responsible for the observed ciprofloxacin resistance (Table $\mathbf{1}$ ).

\section{EFFLUX PUMPS}

The role of efflux pumps in conferring antibiotic resistance and multi-drug resistances in bacteria has been extensively studied and reviewed (Poole, 2004; Piddock, 2006; Martinez, 2009; Nikaido and Pages, 2011). Efflux systems conferring drug resistance typically belong to five main families: the ATP-binding cassette (ABC) transporter, the major facilitator superfamily (MFS), the small multi-drug resistance (SMR), the multi-drug and toxic-compound extrusion (MATE), and the resistance nodulation division (RND) families, the latter present only in Gram-negative bacteria and chromosomally located. The structural genes for these systems can be located on transferable genetic elements and constitute the main acquired mechanisms for drug resistance (e.g., the Tet and the CmlA/FloR efflux systems families for tetracycline and chloramphenicol resistance, respectively). However, bacteria are intrinsically provided with chromosomally encoded efflux systems that are believed to participate in the cell homeostasy, by extruding endo and/or exogenous toxic compounds, heavy metals, virulence factors, quorum sensing signal, etc. In Gram-negative bacteria, RND systems exhibit a wide substrate spectrum, which usually includes drugs of different classes. Nikaido and Pages (2011) have recently reviewed the role of these efflux pumps in a wide range of pathogenic and opportunistic bacterial species such as E. coli, Klebsiella pneumoniae, Enterobacter spp., P. aeruginosa, Acinetobacter baumannii, and the emergent opportunistic Stenotrophomonas maltophilia. Typically, the expression of RND efflux pumps is finely regulated by a dedicated regulator (Coyne et al., 2011). A more complex regulation network, linking efflux to membrane permeability and other cellular functions, is likely to occur in these bacteria, as described for the mar regulon in $E$. coli (reviewed by Grkovic et al., 2002). Some RND efflux genes are not expressed in absence of inducing signal, whereas others exhibit a basal level of expression, and therefore contribute to intrinsic resistance (Coyne et al., 2011). Point mutations in a regulator or in the promoter sequence of RND efflux genes can be responsible for their over-expression and, in turn, for enhanced resistance. Similarly, the acquisition of an insertion sequence, carrying a strong and constitutive promoter, upstream of the regulator or the promoter sequence of RND efflux genes, can also mediate their over-expression and cause drug resistance. These systems have been mostly studied in the context of antibiotic resistance; therefore only little information concerning the natural and physiological mechanisms inducing the expression of RND efflux genes exist. Recently, studies have identified the role of oxidative and nitrosative stress in the activation of MexXY and MexEF-OprN, respectively (Fetar et al., 2011; Fraud and Poole, 2011). These stress signals are likely to occur in the environment and might represent natural inducers of the efflux systems expression. The natural role of efflux systems has been extensively reviewed by Martinez et al. (2009) who concluded that the intrinsic role of efflux in the bacterial physiology has lead to the conservation of the genes coding for efflux pumps among species of the same genus. For example, if the over-expression of $m d f A$ confers MDR to E. coli, a basal expression is involved in the $\mathrm{Na}^{+}\left(\mathrm{K}^{+}\right) / \mathrm{H}^{+}$antiport, that allows the $\mathrm{pH}$ homeostasis of the cell (Lewinson and Bibi, 2001). Efflux pumps conferring resistance to antibiotics, such as the AcrABTolC from Salmonella spp. has also been shown to efflux bile salts, therefore conferring a selective advantage which allowed colonizing and surviving in human or animal intestines (Lacroix et al., 1996). Mosqueda and Ramos (2000) described the contribution of efflux pumps in the cellular extrusion of toluene, an organic solvent, in Pseudomonas putida. This species, able to grow on the liquid interface of water and toluene and to survive in highly contaminated environments, extrudes the solvent by the TtgABC pump. The genes coding for this RND efflux pump usually exhibit a basal expression level but are induced by the presence of toluene in the medium. In water sediment, Groh et al. (2007) demonstrated that a MexF-like pump from Shewanella oneidensis, further than contributing to resistance to tetracycline and chloramphenicol, confers an increased fitness in anoxic environments. The underlying mechanism is unclear but could involve the extrusion of toxic compounds. A well documented role, for some efflux pumps, is their involvement in the cell to cell communication. This function has been demonstrated for MexAB-OprM in P. aeruginosa (Evans et al., 1998), BpeAB-OprB in Burkholderia pseudomallei (Chan and Chua, 2005) and AcrAB-TolC in Enterobacteriaceae (Rahmati et al., 2002). These RND pumps, further than extruding homoserine lactones, are also able to confer MDR. Moreover, several reports have shown that efflux pumps, notably from the RND family, are involved in mechanisms leading to bacterial virulence. For example, Piddock (2006) highlighted the crucial role of efflux pumps in extruding abiotic substances such as flavonoids during plant colonization and in establishing virulence. In antibiotic producing bacteria, efflux pumps play a crucial role as a self defense mechanism by extruding the bioactive secondary metabolites. For instance, an efflux-mediated self-resistance has been developed in the oxytetracycline-producing Streptomyces rimosus (Petkovic et al., 2006). Bacteria living in the same habitat, being exposed to the produced antibiotics, could either adapt their intrinsic mechanisms, e.g., by the over-expression of an efflux pump, or acquire by horizontal gene transfer the resistance mechanism from the producers. The first option would require a point mutation to 
over-express a pre-existing efflux system able to pump out the toxic compound, whereas the second pathway would involve the mobilization and transfer of the gene coding for the self-protecting mechanism. Thus, efflux pumps had an ecological role much before they conferred drug resistances in clinics, as they constitute a selective advantage in presence of competing microorganisms. The massive usage of these drugs has further selected optimized mechanisms and enhanced their spread. The role of mobile and mobilizing genetic elements, such as insertion sequences, integrons, transposons, and plasmids, were critical for a successful and rapid spread. Nikaido and Pages (2011) have observed that the rise of resistance due to efflux pumps mechanisms in clinics is tightly linked to the sub-inhibitory concentration of the antibiotics during clinical therapies. Consequently, the appearance of this kind of resistance favors the emergence of other mechanisms such as reduced membrane permeability to drugs, increase of point mutation in the drug target genes or activation of enzymatic resistance mechanisms. It would be of interest to investigate this aspect of resistance development in environmental habitats, where the concentration of antibiotics varies dependent on the degree of pollution and where other selective forces are present. Especially, heavy metals, naturally present in the soil, and solvents produced as consequences of metabolic activities, have been demonstrated to be substrates of several efflux pumps conferring multi-drug resistance (Silver and Phung, 1996; Moken et al., 1997). Concerning heavy metals, pumps have the additional role to defend bacteria from a toxic excess and to maintain the proper intra-cellular concentration for co-factors and enzymes (Teitzel et al., 2006). The presence of these compounds in freshwater could therefore select for the over-expression of an intrinsic efflux pump. Some heavy metals efflux genes, notably from the SMR family, are located on R plasmids containing antibiotic resistance genes, and heavy metals may favor the co-selection of these two features. In the environment, maintenance and propagation of antibiotic resistance genes might have been promoted by heavy metals selection (Martinez et al., 2009). Moreover, a causal relationship between pollution of the water environment by antibiotics or other pollutants agents and the selection of bacteria expressing or over-expressing efflux pumps appears conceivable. Hernandez et al. (2011a) have recently demonstrated in vitro how triclosan, a detergent antibiotic used in cosmetic, binds the regulator SmeT of the SmeDEF pump in $S$. maltophilia, leading to the over-expression of the pump and consequent multi-drug resistance. This observation is of major concern since $S$. maltophilia is an aquatic species that can be responsible for nosocomial infection.

Until now, it remains unclear how the efflux pumps contribute to the emergence of resistant bacteria in the environment. It has been demonstrated that an efflux pump over-expression could be coupled with a reduced bacterial fitness. However, this is not a general rule. Sanchez et al. (2002) investigated the fitness of two $P$. aeruginosa mutants over-expressing the MexAB-OprM and MexCD-OprJ efflux pumps, both conferring multi-drug resistance. The authors demonstrated in vitro that the MexAB-OprM over-expressing mutant showed a significantly decreased survival in water compared to the wild type strain, while no significant differences were observed for the second efflux pump mutant. In addition, the production of biofilm in both mutants was not affected if not promoted in the MexCD-OprJ mutant. Production of biofilm implies a higher probability of survival in natural water ecosystem and would thus constitute a beneficial characteristic. Selection in polluted environments of opportunistic species such as $P$. aeruginosa, S. maltophilia, or A. baumannii, over-expressing efflux systems could contribute to the spread of these bacteria and their introduction into clinics. It would be interesting to focus on the above described mechanisms also in water environments, to gain a better understanding of their physiological function and their role in the emergence of bacterial drug resistance.

\section{ACQUISITION OF GENES IN WATER HABITATS AND DEVELOPMENT OF ANTIBIOTIC RESISTANCES}

Acquisition of heterologous genes by lateral transfer largely facilitate the adaptive evolution of bacteria, especially under strong selective pressures. Transfer of exogenous DNA in bacteria may be mediated by plasmids, phages, transposons, genomic islands, or captation of free DNA by transformation. Sengelov and Sorensen (1998) have found that in environments such as bulk water, plasmid transfer from a donor to a recipient cell occur, even at a low frequency. Taylor et al. (2011) have observed that several factors could, not only influence, but also promote gene transfer among bacteria in water environment. One such factor is filter feeding organisms that collect bacteria belonging to different species and concentrate them at high density in a reduced space, facilitating gene exchange. Biofilm matrix in water habitats also creates favorable conditions both for plasmid exchange and transformation process (Molin and Tolker-Nielsen, 2003). Interestingly, Meibom et al. (2005) have demonstrated how chitin present in the crustacean exoskeletons is able to activate the competence status of Vibrio cholerae, and thus enhance transformation by acquisition of exogenous DNA. Although they are not classified as mobile genetic elements, integrons are platforms for genes aggregation, and thus contribute to MDR development. Furthermore, the abundance of integrons in bacterial communities of water habitats seems to be associated with the degree of water bodies' pollution (Wright et al., 2008). Many findings support the crucial role of genetic transfer in water habitats mediated by phages (Ripp and Miller, 1995).

\section{INTEGRONS}

Several studies have highlighted the crucial role of integrons, particularly class 1 integrons, in the evolution of antibiotic resistances in clinics (Cambray et al., 2010). Indeed, class 1 integrons are not only platforms for genes aggregation, leading to the establishment of multi-drug resistance, but their localization on mobile genetic elements such as plasmids and transposons favor the spread of several genes in a unique transfer event. Recently, studies on environmental microbial communities have demonstrated that integrons of class 1 are largely present in the environment. Gillings et al. (2008) have provided evidences that the clinical class 1 integrons originated from environmental bacterial communities. The authors observed that class 1 integrons isolated from environmental samples do not carry any antibiotic resistance gene and harbored the qac gene cassettes, which is responsible for the bacterial resistance to quaternary ammoniums by efflux. Clinical class 1 integrons would have arisen from environmental ones by integration on a Tn402-like transposon, which then 
disseminated in human commensals and pathogens. The presence of the qac gene has conferred a selective advantage to adapt in clinical environments, where bacteria are often challenged by disinfectants. The establishment of class 1 integrons in clinical strains has later on enabled the acquisition of antibiotic resistances positively selected by the usage of drugs. This hypothesis is also supported by the fact that clinical class 1 integrons demonstrated similar structures among them, in terms of integrases and recombination site, inferring a common ancestor. Gaze et al. (2005) have demonstrated how pollution of water bodies and their sediments with quaternary ammonium compounds, directly select for bacteria harboring qacE gene cassettes, located on the class 1 integrons. Furthermore, evidence of selection of bacteria harboring class 1 integrons in water bodies contaminated by industrial waste has been provided by Wright et al. (2008). The authors demonstrated that the contamination of freshwater with heavy metals correlated positively with a higher abundance of class 1 integrons in the bacterial community. More recently, Gaze et al. (2011) showed in sewage sludge and pig slurry that the prevalence of class 1 integrons and of qac genes was higher in bacteria exposed to detergents and/or antibiotic residues. All these studies demonstrate that pollution of water bodies with different agents increases the risk of selection and spread of integron structures. These genetic structures may be acquired by bacterial species that play role as shuttle between environment and clinics, constituting gene vectors for further dissemination in nosocomial bacteria.

\section{PHAGES}

Phages are major constituents of environmental ecosystems, in particular freshwater (Weinbauer, 2004; Srinivasiah et al., 2008). Their abundance is usually higher than bacterial abundance and, since a significant fraction of the prokaryotic community is infected with phages in aquatic systems, phages are likely to play an important role in horizontal gene transfer. Parsley et al. (2010) have proven the presence of $\beta$-lactamases genes in the viral metagenome of an activated sludge, confirming that transduction events may be responsible for the propagation of antibiotic resistance genes in these environments. Interestingly, ColomerLluch et al. (2011) demonstrated the presence of bla $a_{\mathrm{TEM}}$ and $b l a_{\mathrm{CTX}-\mathrm{M}}$, the most common genes conferring $\beta$-lactams resistance in Enterobacteriaceae, and mecA, responsible for methicillin resistance in Staphylococcus aureus, in phage DNA isolated from a waste water treatment plant and the natural water of the receiving river.

The presence of mecA in the phage fraction of natural freshwater is of great sanitary concern because of the threat represented by methicillin resistant Staphylococcus aureus (MRSA) infections, both in hospitals and communities (Campanile et al., 2011). This finding is also of interest for the understanding of the propagation of this gene. mecA codes for a protein with a low affinity to penicillin (PBP2a), conferring methicillin resistance. This gene is located on a mobile genomic element, the staphylococcal cassette chromosome (SCCmec), and has been reported only from the Staphylococcus genus from clinics. Baba et al. (2009) have characterized a methicillin resistance gene complex, mecIR $A_{m}$, which could be the progenitor of SCCmec observed in clinical MRSA, from a strain of Macrococcus caseolyticus (closely related to $S$. aureus), isolated from animal meat. Interestingly, Tsubakishita et al. (2010) found a mecA gene in S. fleurettii chromosomally located and not associated to the SCCmec element. Thus, the authors advanced the hypothesis that $S$. fleurettii, an animal related species, is the progenitor of this resistance mechanism. The mecA gene has been reported rarely from natural water, but Schwartz et al. (2003) detected mecA in hospital waste waters. Later, Bockelmann et al. (2009) have reported the sporadic presence of mecA in a ground water recharge system. Kassem et al. (2008) described the presence of the mecA gene in 18 Proteus vulgaris, four M. morganii, and three Enterococcus faecalis isolated from surface water. A ca. $250 \mathrm{bp}$-sequence of $m e c \mathrm{~A}$ from one representative isolate of $P$. vulgaris, M. morganii, and E. faecalis was found to exhibit $100 \%$ similarity with the $S$. aureus mecA gene. However, this result, which is the first report of $M e c A$ in non-staphylococcal organisms, has never been confirmed by other studies or investigated further. Acquisition by transduction of heterologous genes, particularly of antibiotic resistance genes, might represent an important mechanism of horizontal gene transfer in water bodies. Considering the high concentration of phages in such environments (Weinbauer, 2004; Srinivasiah et al., 2008), transduction constitutes probably one of the main gene transfer mechanisms and of genome evolution for bacteria in water habitats. More studies are needed to understand the impact of phage communities on bacterial evolution and antibiotic resistance spread within the water bodies.

\section{ORIGINS OF ACQUIRED ANTIBIOTIC RESISTANCE MECHANISMS}

Recently, D'Costa et al. (2011) have reported a metagenomic analysis of the Beringian permafrost, which is 30,000 years old. They showed molecular evidences of the ancient origins of antibiotic resistances, detecting $\beta$-lactamases genes, vanX-like, component of the vancomycin resistance operon, and tet $\mathrm{M}$, coding for a protein protecting the ribosomal target from tetracycline. Sequence analysis revealed that the $\beta$-lactamases genes recovered from the permafrost demonstrated an amino-acid homology (53-84\%) to known $\beta$-lactamases from $\beta$-lactams producing Streptomyces. The tet $\mathrm{M}$ sequences revealed a high similarity to the genes coding for the ribosomal protection protein of actinomycetes. The vanX sequence showed a similarity to the vanX gene recovered in pathogenic vancomycin resistant enterococci (VRE) and to the vanX gene from Amycolatopsis orientalis. This environmental species, belonging to the actinobacteria phylum, is a natural producer of vancomycin, and very likely the progenitor of the van genes operons, responsible for resistance to vancomycin. The integration of the van operons on transposons and on conjugative plasmids has enhanced their spread (Courvalin, 2006). Reports of VRE in freshwater have been provided by several authors (Talebi et al., 2008; Lata et al., 2009; Luczkiewicz et al., 2010). Interestingly, Schwartz et al. (2003) detected vanA genes in the biofilm of drinking water supplies, in the absence of enterococci, demonstrating the lateral transfer of this gene. Notably, the progenitors of these resistance genes are soil bacteria thus most likely, a shuttle has been responsible for the introduction of these genes into the commensal bacterial community and afterward into the pathogenic species. 


\section{FLUOROOUINOLONES RESISTANCE BY TARGET PROTECTION}

Resistance mechanisms originating from bacterial population of water bodies are less well documented than from soil organisms. However, the significance of water bodies as natural source for resistance mechanisms is similar compared to the soil. For example, a well known example is provided by the acquired fluoroquinolones resistance genes of the qnr family. qnr genes encode proteins binding the bacterial DNA gyrase, thus preventing the interaction of the antibiotic with its target. Generally, the presence of these acquired genes does not confer a high level of fluoroquinolones resistance, but provides a selective advantage in the presence of these drugs, even at low concentrations (RodriguezMartinez et al., 2011). Further, this protecting mechanism and the associated low level resistance may favor the emergence of strains with higher resistances to fluoroquinolones by mutations in the QRDR, quinolones resistance determining region, and/or by overexpressing efflux systems. Several aquatic bacterial species have been proposed as progenitors for these genes families. Poirel et al. (2005b) reported evidences that the qnrA gene located on plasmids and found in clinical isolates of fluoroquinolones resistant Enterobacteriaceae, is derived from the chromosome of Shewanella algae, a bacterial species present in marine and freshwater. The authors advanced the hypothesis that the gene jumped from the environmental species to Enterobacteriaceae probably under pressure of antibiotic usage. Beaber et al. (2004) have demonstrated that the presence of fluoroquinolones induces the SOS bacterial repair system, which in turn promotes horizontal gene transfer. Poirel et al. (2005a) conducted further investigations in order to understand the origin of this antibiotic resistance mechanism. Their study highlighted that the chromosomes of water borne bacteria, Vibrio vulnificus, Vibrio parahaemolyticus, and Photobacterium profundum harbored qnr-like genes with homology (40-67\% identity) to the plasmidic $q n r \mathrm{~A}, q n r \mathrm{~B}$, and $q n r \mathrm{~S}$ genes described in clinical Enterobacteriaceae.

Interestingly, qnrA has been observed frequently associated with the insertion sequence ISCR1, a genetic element able to mobilize adjacent genes. Toleman et al. (2006) hypothesized that the ISCR1 mediated mobilization of $q n r \mathrm{~A}$, as well as a further localization on a class 1 integron to form a so-called complex integron structure. The authors formulated that this complex integron structure is responsible for the successful dissemination of $q n r \mathrm{~A}$ gene. Arsène and Leclercq (2007) investigated the intrinsic resistance of E. faecalis to fluoroquinolones and found that this species is provided with a chromosomal qnr-like gene, which contributes to resistance against fluoroquinolones. Soon afterward, Sánchez et al. (2008) discovered that the aquatic bacterium S. maltophilia is a sink of $q n r$ genes and the chromosomally located Smqnr gene identified in this species is able to confer resistance to fluoroquinolones in heterologous species. In 2010, Velasco et al. (2010) reported qnr-like genes from Serratia marcescens, an environmental species. These genes, called Smaqnr, were largely present in the chromosome of the genus. Recently, Jacoby et al. (2011) have highlighted that the Citrobacter spp. chromosome constitutes a reservoir for the qnrB fluoroquinolones resistance gene. The presence of qnr genes on the chromosome of phylogenetically distant bacterial species (Shewanella, Stenotrophomonas, Vibrio, Enterococcus, Serratia, Citrobacter), suggests an ancestral role of this antibiotic resistance mechanism. Hernandez et al. (2011b) postulated a regulatory role for the Qnr proteins. Indeed, by interacting with the DNA gyrase, Qnr may protect the DNA gyrase against toxic DNA substances and indirectly modulate gene expression in response to environmental changes. Moreover, a beneficial role of these protecting mechanisms has been shown for $q n r \mathrm{~A} 3$, which confers a fitness advantage to the bacteria, favoring its dissemination. The fitness advantage was found abolished when qnrA3 was carried by large multi-drug resistance plasmids (Michon et al., 2011). The activation of $q n r \mathrm{~B}$ expression by the SOS-response system could also have an implication in the conservation of such mechanism. As ciprofloxacin induces the SOS-response system, it activates its corresponding resistance mechanisms (Da Re et al., 2009). Several studies have reported $q n r$ genes in heterologous species from water habitats. Cattoir et al. (2008) recovered from the Seine River A. punctata and A. media harboring qnrS2. Similarly, Picao et al. (2008) detected qurS genes in Aeromonas allosaccarophila from the Lugano Lake, in Switzerland. A qnrVC4 allele was isolated from aquatic environments in A. punctata by Xia et al. (2010). All these reports demonstrate that the Aeromonas genus represents a reservoir for fluoroquinolones resistance mediated by Qnr. Our own studies characterized a qnrS determinant in E. coli belonging to ST131 isolated from freshwater of a Ukrainian River (Lupo et al., submitted). Similarly, Dhanji et al. (2011) isolated E. coli strains belonging to ST131 harboring a qnrS allele from the Thames River (Table 1). These findings reflect a spread of these resistance mechanisms by geographical and clonal means and highlight the potential of rivers in the dissemination of international resistant clones.

\section{ACOUIRED EFFLUX MECHANISMS}

Another acquired fluoroquinolones resistance mechanisms is represented by efflux mechanisms. The qepA gene, initially characterized on a conjugative plasmid from a clinical isolate of $E$. coli (Perichon et al., 2007), encodes a MFS efflux pump. It has been recently recovered from the metagenome of river sediments impacted by improperly managed urban waste waters (Cummings et al., 2011). Environmental reports of this gene are rare; however, Deng et al. (2011) have highlighted the possible spread of this gene by animal and human related bacterial strains in water compartments. Similarly, the detection of the OqxAB efflux pump, conferring resistance to fluoroquinolones, olaquindox, and chloramphenicol, remains rare in environmental samples. The oqx $\mathrm{AB}$, found on a conjugative plasmid in E. coli strains, represents the only example of transferable RND efflux pumps, so far (Hansen et al., 2004). Recently, Zhao et al. (2010) have reported an E. coli strain, isolated from a water pond in a farm environment, harboring the oqx $\mathrm{AB}$ gene (Table 1).

Resistance by acquired efflux mechanisms to other drug classes than fluoroquinolones has been extensively reported in the literature (Poole, 2004; Piddock, 2006; Nikaido and Pages, 2011). Studies conducted in water habitats such as aquaculture, impacted by anthropogenic activities, and notably by the application of antibiotics, demonstrated the risk of selection of acquired efflux pumps. Fernandez-Alarcon et al. (2010) reported the presence of different Gram-negative species from aquacultures in Chile expressing the floR gene, which codes for a chloramphenicol and florfenicol 
exporter, drugs intensively used in veterinary medicine. Alarmingly, those strains resistant to florfenicol also demonstrated a multi-drug resistance, suggesting a process of co-selection. Gordon et al. (2008) characterized the floR gene, in Aeromonas bestiarum strains from freshwater streams in France, located on a $25-\mathrm{kb}$-plasmid harboring also the tetracycline efflux gene tet $(\mathrm{Y})$, strB-strA, conferring resistance to streptomycin, and sul2 conferring resistance to sulfonamides (Table 1). Interestingly, this plasmid contained sequences with high nucleotide homologies to other genetic elements recognized in different aquatic bacterial species such as V. cholerae and Photobacterium damselae. This demonstrated the contribution of horizontal gene transfer in the spread of these resistances in aquatic habitats. Furthermore, genes encoding tetracycline efflux mechanisms have been found to circulate between farm environments and ground water (Aminov et al., 2002). Propagation of tetracycline resistance genes, by efflux or by ribosomal protection, has been linked to the extensive usage of this drug class in animal feeding, and although the usage of this antibiotic has been restricted, tetracycline resistance genes seem to persist in the food chain and in the environment.

\section{THE ENZYMATIC $\beta$-LACTAMS RESISTANCE}

Resistance to $\beta$-lactams has spread worldwide. The low toxicity of these molecules and the broad spectrum of action of some of them make $\beta$-lactams the most prescribed antibiotic drug class and propagation of resistance constitutes therefore a major clinical concern. Studies have highlighted that the rise of the bacterial resistance against $\beta$-lactams is related to the usage of the drug in clinics, both because of selection of resistant bacteria and by promoting the mobilization of the genes responsible for such resistances (Bush and Fisher, 2011). Similarly, the presence of antibiotics in water environments could promote the selection of antibiotic resistant strains. Detecting and measuring the concentration of antibiotics or intermediary products from their metabolization and degradation in water medium is difficult, mainly because of the lack of standardized methods (Pérez-Parada et al., 2011). However, different studies described analytical methods to investigate pollution of freshwater by antibiotic compounds (Bailon-Perez et al., 2009; Ibanez et al., 2009) and antibiotics, including $\beta$-lactams, have been found to contaminate significantly several rivers (Pei et al., 2006; Jiang et al., 2011; Yang et al., 2011). A recent report from Pérez-Parada et al. (2011) has demonstrated the presence of compounds derived from amoxicillin in river effluent water. Although a selection due to these compounds has not been demonstrated, a corresponding risk cannot be excluded.

The most prevalent mechanism of $\beta$-lactams resistance in Gram-negative bacteria has been, for a long time, the enzymatic inactivation mediated by penicillinases such as TEM, SHV, and the extended spectrum $\beta$-lactamases (ESBLs) derived from these families (Coque et al., 2008). In the last decade, bla $a_{\mathrm{TEM}}$ and bla $a_{\mathrm{SHV}}$, genes have become less frequently detected in clinics and have been replaced by the more recently described bla $a_{\text {CTX-M }}$ (Bonnet, 2004). CTX-M enzymes represent a special concern in clinics due to the extended spectrum of action and to its global, successful spread that has occurred in bacteria responsible for nosocomial and community acquired infections (Pitout et al., 2005). In 1963, $b l a_{\mathrm{TEM}}$ has been reported for the first time, located on a plasmid.
All the currently known bla TEM genes have been documented to derive from the first characterized allele (Barlow and Hall, 2002). However, the origin of this mechanism has not been elucidated until now. The K. pneumoniae chromosome is thought to be the origin of bla $a_{\mathrm{SHV}}$, even if the physiological role of this mechanism remains unknown (Haeggman et al., 2004). CTX-M enzymes have been extensively investigated in clinics and more recently reported from environmental samples. Presence of $b a_{\mathrm{CTX}-\mathrm{M}}$ in bacteria from freshwater (Dhanji et al., 2011; Lupo et al., submitted), water sediment ( $\mathrm{Lu}$ et al., 2010), or water-associated birds (Randall et al., 2011) constitutes further reservoirs and shuttles for these resistance determinants (Table 1). Based on aminoacidic homology, the bla $a_{\mathrm{CTX}-\mathrm{M}}$ genes are sorted in four groups: bla $a_{\mathrm{CTX}-\mathrm{M}-1}$, $b l a_{\text {CTX-M-2 }}, b l a_{\text {CTX-М-8 }}, b l a_{\text {CTX-M-9 }}$ (Pitout et al., 2005). The progenitor of each gene group has been found located on the chromosome of Kluyvera spp., of the Enterobacteriaceae family. Mobilization events from the ancestor genes have given rise to the clinically relevant mechanisms. In detail, bla $a_{\mathrm{CTX}-\mathrm{M}-1}$ and bla $a_{\mathrm{CTX}-\mathrm{M}-2}$ derived from Kluyvera ascorbata (Humeniuk et al., 2002; Rodriguez et al., 2004), bla CTX-M-8 $_{\text {and }}$ bla CTX-M-9 $_{\text {from Kluyvera georgiana (Poirel }}$ et al., 2002; Canton and Coque, 2006). The Kluyvera genus seems to be a sink of bla $a_{\mathrm{CTX}-\mathrm{M}}$. Indeed, Kluyvera cryocrescens harbors a chromosomal $\beta$-lactamase, KLUC-1, which shares ca. $85 \%$ identity with CTX-M-1 (Bonnet, 2004). To the best of our knowledge, KLUC-1 has not been encountered in clinical isolates, but this species represents a reservoir of a new potential clinical ESBL. Although Kluyvera spp. are considered environmental bacteria and have been found also in water, elucidating the natural habitat of this species may help to evaluate the risk of the propagation of their $\beta$-lactamases. The CTX-M enzymes have been extensively investigated because of the clinical consequences that their spread has caused. However, many class A $\beta$-lactamases are chromosomally located in several members of Enterobacteriaceae and could constitute, if integrated on mobile elements, future mechanisms emerging in clinics. Bellais et al. (2001) discovered a chromosomal $\beta$-lactamase in Rahnella aquatilis (RAHN-1), which had similar-

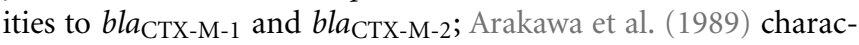
terized KOXY from Klebsiella oxytoca; Perilli et al. (1991) MAL-1 in Citrobacter diversus; Peduzzi et al. (1994) CUM-A in P. vulgaris; Liassine et al. (2002) HUG-A from Proteus penneri; Peduzzi et al. (1997) SFO-1 from Serratia fonticola; Seoane and Garcia Lobo (1991) YENT from Yersinia enterocolitica; Vimont et al. (2002) ERP-1 from Erwinia persicina; Walckenaer et al. (2004) PLA-1 and ORN-1A from Raoultella planticola and Raoultella ornithinolytica, respectively. The above mentioned list provides only some examples: Bush and Fisher (2011) have reviewed that almost 600 class A $\beta$-lactamases naturally occur and have been reported in 2011 . Worryingly, mechanisms exhibiting a spectrum of activity extended to carbapenems are emerging in clinics (Rossolini, 2005; Queenan and Bush, 2007). VIM, IMP, KPC, some OXA, and the newly described NDM-1 represent examples of these enzymes. The emergence of KPC (K. pneumoniae carbapenemase) was described in 2001 (Yigit et al., 2001) and this enzyme has been found to spread worldwide and among several bacterial species such as Enterobacteriaceae, P. aeruginosa, and A. baumannii (Bush and Fisher, 2011). The crucial molecular vector of its spread has been recognized by Naas et al. (2008), who characterized the location of $b l a_{\mathrm{KPC}}$ gene on 
a Tn-3-like transposon, the Tn4401, probably responsible for the original mobilization of this gene. The transposon contains several sequences encoding transposases or insertion sequences derived from environmental bacterial species, but the ancestral host of this enzyme has not been identified, so far. Recently Chagas et al. (2011) have detected K. pneumoniae producing KPC in an effluent receiving hospital waste water, highlighting an environmental vector for the dissemination of these enzymes (Table 1). VIM enzymes have been rarely reported from environmental isolates. Scotta et al. (2011) isolated Brevundimonas diminuta, Rhizobium radiobacter, Pseudomonas monteilii, P. aeruginosa, O. anthropi, and Enterobacter ludwigii strains producing VIM enzymes, again from an effluent receiving the waste water of a hospital. Previously, Quinteira et al. (2005) isolated a strain of Pseudomonas pseudoalcaligenes harboring bla $a_{\text {VIM }}$ from a hospital wastewater effluent (Table 1). Probably, the presence of VIM producer species in the environment is due to nosocomial selective conditions and contamination by wastewater from hospitals. However, the detection of bla $a_{\mathrm{VIM}}$ in different environmental species from freshwater highlights the potential of water as a reservoir for these genes and as a vector facilitating their spread. Concerning IMP enzymes, so far, a unique report has been provided by Pellegrini et al. (2009), in a strain of P. fluorescens recovered from waste water (Table 1 ). A carbapenemase activity is also exhibited by several class $D \beta$-lactamases, among which the families of OXA-23, OXA-40, OXA-58, and OXA-51 are associated to A. baumannii (Poirel et al., 2010). This opportunistic pathogen, provided with an intrinsic but silent $b l a_{\text {OXA51-like gene, is widely }}$ distributed in nature. The origin of $b l a_{\text {OXA-40 }}$ and bla $a_{\text {OXA-58-like }}$ genes remains unknown but Poirel et al. (2008) have characterized

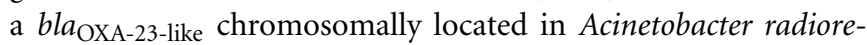
sistens, suggesting that this species is the progenitor for OXA-23. Moreover, A. baumannii isolates carrying bla $a_{\mathrm{OXA}-23}$ have been detected in river (Girlich et al., 2010) and wastewater from hospitals (Ferreira et al., 2011, Table 1). OXA-48 represents another class D carbapenemase that dramatically spreads among Enterobacteriaceae. This latter enzyme is supposed to originate from the chromosome of the water borne species S. oneidensis (Poirel et al., 2004). Recently, $S$. marcescens strains harboring bla OXA-48 have been isolated from a river in Morocco (Potron et al., 2011), demonstrating the risks for their dissemination in water habitats (Table 1). The recent emergence and dramatic spread of NDM-1 enzyme in clinical isolates of A. baumannii and Enterobacteriaceae, has focused major attentions. Usually, strains harboring this broad spectrum carbapenemase gene demonstrate a multi-drug resistant phenotype and a wide set of virulence genes (Walsh et al., 2011). The carriage of bacteria harboring $b l a_{\mathrm{NDM}-1}$ by healthy individuals has lead researchers to investigate the source of this gene. Walsh et al. (2011) recently demonstrated the presence of different bacterial species ( $P$. aeruginosa, Achromobacter spp., and Kingella denitrificans) harboring $b l a_{\mathrm{NDM}-1}$ in tap water used as drinking water in India (Table 1). This finding is closing the transmission circle and explains the fast and successful dissemination of this gene. Several genes encoding carbapenemase enzymes have been found chromosomally located in bacterial species of environmental origin and water related, for instance the sme gene on the chromosome of $S$. marcescens, and the $s f c$ gene on the $S$. fonticola chromosome (Naas and Nordmann, 1994; Henriques et al., 2004).
The water borne $S$. maltophilia also harbors a gene coding for the L1 carbapenemase. Avison et al. (2001) have elucidated that this gene is located on a plasmid-like element considered intrinsic to S. maltophilia.

Class C $\beta$-lactamases located on plasmids (CMY, MIR, DHA, and ACT) have been found worldwide from several sources (Jacoby, 2009). Water borne bacteria, such as A. hydrophila, M. morganii, $H$. alvei, and shuttle species between water and gut such as Citrobacter freundii, Enterobacter asburiae, have been proposed to be the progenitors of the most commonly encountered plasmidic ampC genes detected in clinical isolates. These genes have been reported from Canadian and Korean water bodies (Kim et al., 2008; Mataseje et al., 2009). Schwartz et al. (2003) detected ampC in waste, surface, and drinking water biofilms (Table 1). The presence of antibiotic resistance genes in biofilm matrices, especially in those located in drinking water supplies is of particular concern. Indeed, such biofilm matrices can be a long lasting source of antibiotic resistance genes that can directly spread via the food chain.

\section{CONCLUSION}

The emergence of antibiotic resistance is the consequence of a complex interaction of factors involved in the evolution and spread of resistance mechanisms. The over-usage of antibiotics in clinics has been believed to be the principal element involved in the rise of new resistances. Recently, many more evidences suggest that environmental habitats especially water bodies such as rivers and streams are ideal vectors for the antibiotic resistance dissemination. Here, the propagation of bacteria harboring antibiotic resistance genes can occur spatially along the river. Furthermore, the dispersion of these bacteria in the environment favors the interaction with the autochthonous microbiota, creating new scenarios for the evolution of antibiotic resistances.

In strong contrast to clinics, there are no data available on the epidemiology of antibiotic resistances in the environment, especially for geographically based data. This in turn makes extremely difficult to make any predictions on the risk of spread and emergence of new antibiotic resistances. For this reason we assume that a better knowledge on the environmental reservoir of resistances is fundamental to predict the emergences of new resistances of clinical concern.

It should be noticed that the pollution of water can select antibiotic resistant bacteria. This process, involving notably coselection events, could cause an ecological imbalance leading to the dominance of resistant bacteria and global disturbance of the ecosystems. This latter point highlights the necessity of collecting information and data on the status of the sampling sites when performing a study on antibiotic resistance in freshwater. The development of antibiotic resistances occurs very likely naturally in the environment, but factors like pollution, especially of water bodies, could force the speed of its evolution. A good status of water quality could limit this phenomenon. Despite this, the status of the surface water quality in many countries is still poor. We argue for the implementation of feasible methodologies to characterize quality parameters and detect antibiotic resistance in water bodies, and thus to establish adapted and pragmatic measures to improve water resources. Amelioration of water status is 
of major concern: it can contribute to a direct and local decreased risk for the health of populations living in the vicinity of the freshwater, and lead to more global effects by avoiding that water bodies could constitute reactors for antibiotic resistance emergence and evolution.

\section{REFERENCES}

Alcaide, E., Blasco, M. D., and Esteve, C. (2010). Mechanisms of quinolone resistance in Aeromonas species isolated from humans, water and eels. Res. Microbiol. 161, 40-45.

Ambler, R. P. (1980). The structure of beta-lactamases. Philos. Trans. R. Soc. Lond. B Biol. Sci. 289, 321-331.

Aminov, R. I. (2011). Horizontal gene exchange in environmental microbiota. Front. Microbiol. 2:158. doi:10.3389/fmicb.2011.00158

Aminov, R. I., Chee-Sanford, J. C., Garrigues, N., Teferedegne, B., Krapac, I. J., White, B. A., and Mackie, R. I. (2002). Development, validation, and application of PCR primers for detection of tetracycline efflux genes of gram-negative bacteria. Appl. Environ. Microbiol. 68, 1786-1793.

Aminov, R. I., and Mackie, R. I. (2007). Evolution and ecology of antibiotic resistance genes. FEMS Microbiol. Lett. 271, 147-161.

Arakawa, Y., Ohta, M., Kido, N., Mori, M., Ito, H., Komatsu, T., Fujii, Y., and Kato, N. (1989). Chromosomal beta-lactamase of Klebsiella oxytoca, a new class A enzyme that hydrolyzes broad-spectrum beta-lactam antibiotics. Antimicrob. Agents Chemother. 33, 63-70.

Arsène, S., and Leclercq, R. (2007). Role of a qnr-like gene in the intrinsic resistance of Enterococcus faecalis to fluoroquinolones. Antimicrob. Agents Chemother. 51, 3254-3258.

Avison, M. B., Higgins, C. S., Von Heldreich, C. J., Bennett, P. M., and Walsh, T. R. (2001). Plasmid location and molecular heterogeneity of the $\mathrm{L} 1$ and L2 beta-lactamase genes of Stenotrophomonas maltophilia. Antimicrob. Agents Chemother. 45, 413-419.

Baba, T., Kuwahara-Arai, K., Uchiyama, I., Takeuchi, F., Ito, T., and Hiramatsu, K. (2009). Complete genome sequence of Macrococcus caseolyticus strain JCSCS5402, reflecting the ancestral genome of the humanpathogenic staphylococci. J. Bacteriol. 191, 1180-1190.

Bailon-Perez, M. I., Garcia-Campana, A. M., Del Olmo-Iruela, M., GamizGracia, L., and Cruces-Blanco, C.
(2009). Trace determination of 10 beta-lactam antibiotics in environmental and food samples by capillary liquid chromatography. J. Chromatogr. A 1216, 8355-8361.

Baquero, F., Martinez, J. L., and Canton, R. (2008). Antibiotics and antibiotic resistance in water environments. Curr. Opin. Biotechnol. 19, 260-265.

Barlow, M., and Hall, B. G. (2002). Predicting evolutionary potential: in vitro evolution accurately reproduces natural evolution of the tem beta-lactamase. Genetics 160, 823-832.

Beaber, J. W., Hochhut, B., and Waldor, M. K. (2004). SOS response promotes horizontal dissemination of antibiotic resistance genes. Nature 427, 72-74.

Bellais, S., Poirel, L., Fortineau, N., Decousser, J. W., and Nordmann, P. (2001). Biochemical-genetic characterization of the chromosomally encoded extended-spectrum class A beta-lactamase from Rahnella aquatilis. Antimicrob. Agents Chemother. 45, 2965-2968.

Bockelmann, U., Dorries, H. H., AyusoGabella, M. N., Salgot De Marcay, M., Tandoi, V., Levantesi, C., Masciopinto, C., Van Houtte, E., Szewzyk, U., Wintgens, T., and Grohmann, E. (2009). Quantitative PCR monitoring of antibiotic resistance genes and bacterial pathogens in three European artificial groundwater recharge systems. Appl. Environ. Microbiol. 75, 154-163.

Bonnet, R. (2004). Growing group of extended-spectrum betalactamases: the CTX-M enzymes. Antimicrob. Agents Chemother. 48, $1-14$.

Bush, K. (2010). Alarming betalactamase-mediated resistance in multidrug-resistant Enterobacteriaceae. Curr. Opin. Microbiol. 13, 558-564.

Bush, K., and Fisher, J. F. (2011). Epidemiological expansion, structural studies, and clinical challenges of new beta-lactamases from gramnegative bacteria. Annu. Rev. Microbiol. 65, 455-478.

Cambray, G., Guerout, A. M., and Mazel, D. (2010). Integrons. Annu. Rev. Genet. 44, 141-166.

\section{ACKNOWLEDGMENTS}

Authors' research is financed by the German Federal Ministry of Education and Research (Grant No.: FKZ 02WM1028). We thank the members of the Cost Action TD0803 "Detecting evolutionary hot spots of antibiotic resistances in Europe" for helpful discussion.

Campanile, F., Bongiorno, D., Falcone, M., Vailati, F., Pasticci, M. B. Perez, M., Raglio, A., Rumpianesi, F., Scuderi, C., Suter, F., Venditti, M., Venturelli, C., Ravasio, V., Codeluppi, M., and Stefani, S. (2011). Changing Italian nosocomial-community trends and heteroresistance in Staphylococcus aureus from bacteremia and endocarditis. Eur. J. Clin. Microbiol. Infect. Dis. PMID: 21822974. [Epub ahead of print].

Canton, R., and Coque, T. M. (2006) The CTX-M beta-lactamase pandemic. Curr. Opin. Microbiol. 9, 466-475.

Cattoir, V., Poirel, L., Aubert, C. Soussy, C. J., and Nordmann, P. (2008). Unexpected occurrence of plasmid-mediated quinolone resistance determinants in environmental Aeromonas spp. Emerging Infect. Dis. 14, 231-237.

Chagas, T. P., Seki, L. M., Da Silva, D. M., and Asensi, M. D. (2011). Occurrence of KPC-2-producing Klebsiella pneumoniae strains in hospital wastewater. J. Hosp. Infect. 77, 281.

Chan, Y. Y., and Chua, K. L. (2005). The Burkholderia pseudomallei BpeABOprB efflux pump: expression and impact on quorum sensing and virulence. J. Bacteriol. 187, 4707-4719.

Colomer-Lluch, M., Jofre, J., and Muniesa, M. (2011). Antibiotic resistance genes in the bacteriophage DNA fraction of environmental samples. PLoS ONE 6, e17549. doi:10.1371/journal.pone. 0017549

Coque, T. M., Baquero, F., and Canton, R. (2008). Increasing prevalence of ESBL-producing Enterobacteriaceae in Europe. Euro Surveill. 13, 1-11.

Courvalin, P. (2006). Vancomycin resistance in Gram-positive cocci. Clin. Infect. Dis. 42(Suppl. 1) S25-S34.

Coyne, S., Courvalin, P., and Perichon, B. (2011). Efflux-mediated antibiotic resistance in Acinetobacter spp. Antimicrob. Agents Chemother. 55, 947-953.

Cummings, D. E., Archer, K. F., Arriola, D. J., Baker, P. A., Faucett, K. G., Laroya, J. B., Pfeil, K. L., Ryan, C. R., Ryan, K. R., and Zuill, D. E. (2011). Broad dissemination of plasmidmediated quinolone resistance genes in sediments of two urban coastal wetlands. Environ. Sci. Technol. 45, 447-454.

Da Re, S., Garnier, F., Guerin, E., Campoy, S., Denis, F., and Ploy, M. C. (2009). The SOS response promotes qnrB quinolone-resistance determinant expression. EMBO Rep. 10, 929-933.

D'Costa, V. M., King, C. E., Kalan, L., Morar, M., Sung, W. W., Schwarz, C., Froese, D., Zazula, G., Calmels, F., Debruyne, R., Golding, G. B., Poinar, H. N., and Wright, G. D. (2011). Antibiotic resistance is ancient. Nature 477, 457-461.

Deng, Y., Zeng, Z., Chen, S., He, L., Liu, Y., Wu, C., Chen, Z., Yao, Q., Hou, J. Yang, T., and Liu, J. H. (2011). Dissemination of IncFII plasmids carrying $r m t \mathrm{~B}$ and qepA in Escherichia coli from pigs, farm workers and the environment. Clin. Microbiol. Infect. 17, 1740-1745.

Depledge, M. (2011). Pharmaceuticals: reduce drug waste in the environment. Nature 478, 36

Dhanji, H., Murphy, N. M., Akhigbe, C. Doumith, M., Hope, R., Livermore, D. M., and Woodford, N. (2011). Isolation of fluoroquinolone-resistant O25b:H4-ST131 Escherichia coli with CTX-M-14 extended-spectrum beta-lactamase from UK river water. J. Antimicrob. Chemother. 66, 512-516.

Evans, K., Passador, L., Srikumar, R., Tsang, E., Nezezon, J., and Poole, K. (1998). Influence of the MexAB-OprM multidrug efflux system on quorum sensing in Pseudomonas aeruginosa. J. Bacteriol. 180, 5443-5447.

Fernandez-Alarcon, C., Miranda, C. D., Singer, R. S., Lopez, Y., Rojas, R., Bello, H., Dominguez, M., and Gonzalez-Rocha, G. (2010). Detection of the floR gene in a diversity of florfenicol resistant Gram-negative bacilli from freshwater salmon farms in Chile. Zoonoses Public Health 57, 181-188.

Ferreira, A. E., Marchetti, D. P., De Oliveira, L. M., Gusatti, C. S., Fuentefria, D. B., and Corcao, G. (2011) Presence of OXA-23-producing isolates of Acinetobacter baumannii in wastewater from hospitals in southern Brazil. Microb. Drug Resist. 17, 221-227. 
Fetar, H., Gilmour, C., Klinoski, R., Daigle, D. M., Dean, C. R., and Poole, K. (2011). mexEF-oprN multidrug efflux operon of Pseudomonas aeruginosa: regulation by the MexT activator in response to nitrosative stress and chloramphenicol. Antimicrob. Agents Chemother. 55, 508-514.

Figueira, V., Vaz-Moreira, I., Silva, M., and Manaia, C. M. (2011). Diversity and antibiotic resistance of Aeromonas spp. in drinking and waste water treatment plants. Water Res. 45, 5599-5611.

Fraud, S., and Poole, K. (2011). Oxidative stress induction of the MexXY multidrug efflux genes and promotion of aminoglycoside resistance development in Pseudomonas aeruginosa. Antimicrob. Agents Chemother. 55, 1068-1074.

Gaze, W. H., Abdouslam, N., Hawkey, P. M., and Wellington, E. M. (2005). Incidence of class 1 integrons in a quaternary ammonium compoundpolluted environment. Antimicrob. Agents Chemother. 49, 1802-1807.

Gaze, W. H., Zhang, L., Abdouslam, N. A., Hawkey, P. M., Calvo-Bado, L., Royle, J., Brown, H., Davis, S., Kay, P., Boxall, A. B., and Wellington, E. M. (2011). Impacts of anthropogenic activity on the ecology of class 1 integrons and integron-associated genes in the environment. ISME J. 5, 1253-1261.

Gillings, M., Boucher, Y., Labbate, M., Holmes, A., Krishnan, S., Holley, M., and Stokes, H. W. (2008). The evolution of class 1 integrons and the rise of antibiotic resistance. J. Bacteriol. 190, 5095-5100.

Girlich, D., Poirel, L., and Nordmann, P. (2010). First isolation of the bla OXA-23 carbapenemase gene from an environmental Acinetobacter baumannii isolate. Antimicrob. Agents Chemother. 54, 578-579.

Gordon, L., Cloeckaert, A., Doublet, B., Schwarz, S., Bouju-Albert, A., Ganiere, J. P., Le Bris, H., Le FlecheMateos, A., and Giraud, E. (2008). Complete sequence of the floRcarrying multiresistance plasmid pAB5S9 from freshwater Aeromonas bestiarum. J. Antimicrob. Chemother. 62, 65-71.

Grkovic, S., Brown, M. H., and Skurray, R. A. (2002). Regulation of bacterial drug export systems. Microbiol. Mol. Biol. Rev. 66, 671-701.

Groh, J. L., Luo, Q., Ballard, J. D., and Krumholz, L. R. (2007). Genes that enhance the ecological fitness of Shewanella oneidensis MR-1 in sediments reveal the value of antibiotic resistance. Appl. Environ. Microbiol. 73, 492-498.
Gullberg, E., Cao, S., Berg, O. G., Ilback, C., Sandegren, L., Hughes, D., and Andersson, D. I. (2011). Selection of resistant bacteria at very low antibiotic concentrations. PLoS Pathog. 7, e1002158. doi:10.1371/journal.ppat.1002158

Haeggman, S., Lofdahl, S., Paauw, A., Verhoef, J., and Brisse, S. (2004) Diversity and evolution of the class A chromosomal $\beta$-lactamase gene in Klebsiella pneumoniae. Antimicrob. Agents Chemother. 48, 2400-2408.

Hansen, L. H., Johannesen, E., Burmolle, M., Sorensen, A. H., and Sorensen, S. J. (2004). Plasmidencoded multidrug efflux pump conferring resistance to olaquindox in Escherichia coli. Antimicrob. Agents Chemother. 48, 3332-3337.

Hawkey, P. M. (2008). The growing burden of antimicrobial resistance. J. Antimicrob. Chemother. 62(Suppl. 1), i1-i9.

Henriques, I., Moura, A., Alves, A., Saavedra, M. J., and Correia, A. (2004). Molecular characterization of a carbapenem-hydrolyzing class A beta-lactamase, SFC-1, from Serratia fonticola UTAD54. Antimicrob. Agents Chemother. 48, 2321-2324.

Hernandez, A., Ruiz, F. M., Romero, A., and Martinez, J. L. (2011a). The binding of triclosan to SmeT, the repressor of the multidrug efflux pump SmeDEF, induces antibiotic resistance in Stenotrophomonas maltophilia. PLoS Pathog. 7, e1002103. doi:10.1371/journal.ppat.1002103

Hernandez, A., Sanchez, M. B., and Martinez, J. L. (2011b). Quinolone resistance: much more than predicted. Front. Microbiol. 2:22. doi:10.3389/fmicb.2011.00022

Humeniuk, C., Arlet, G., Gautier, V., Grimont, P., Labia, R., and Philippon, A. (2002). Betalactamases of Kluyvera ascorbata, probable progenitors of some plasmid-encoded CTX-M types. Antimicrob. Agents Chemother. 46, 3045-3049.

Ibanez, M., Guerrero, C., Sancho, J. V., and Hernandez, F. (2009). Screening of antibiotics in surface and wastewater samples by ultrahigh-pressure liquid chromatography coupled to hybrid quadrupole time-of-flight mass spectrometry. $J$. Chromatogr. A 1216, 2529-2539.

Jacoby, G. A. (2009). AmpC betalactamases. Clin. Microbiol. Rev. 22, 161-182.

Jacoby, G. A., Griffin, C. M., and Hooper, D. C. (2011). Citrobacter spp. as a source of $q n r \mathrm{~B}$ alleles. Antimicrob. Agents Chemother. 55, 4979-4984.
Jiang, L., Hu, X., Yin, D., Zhang, H., and $\mathrm{Yu}, \mathrm{Z}$. (2011). Occurrence, distribution and seasonal variation of antibiotics in the Huangpu River, Shanghai, China. Chemosphere 82 , 822-828.

Kassem, II, Esseili, M. A., and Sigler, $\mathrm{V}$. (2008). Occurrence of mecA in nonstaphylococcal pathogens in surface waters. J. Clin. Microbiol. 46, 3868-3869.

Kim, J., Kang, H. Y., and Lee, Y. (2008). The identification of CTX-M-14 TEM-52, and CMY-1 enzymes in Escherichia coli isolated from the Han River in Korea. J. Microbiol. 46, 478-481.

Lacroix, F. J., Cloeckaert, A., Grepinet, O., Pinault, C., Popoff, M. Y., Waxin, H., and Pardon, P. (1996). Salmonella typhimurium acrB-like gene: identification and role in resistance to biliary salts and detergents and in murine infection. FEMS Microbiol. Lett. 135, 161-167.

Lambert, P. A. (2005). Bacterial resistance to antibiotics: modified target sites. Adv. Drug Deliv. Rev. 57, 1471-1485.

Lata, P., Ram, S., Agrawal, M., and Shanker, R. (2009). Enterococci in river Ganga surface waters: propensity of species distribution, dissemination of antimicrobial-resistance and virulence-markers among species along landscape. BMC Microbiol. 9 140. doi:10.1186/1471-2180-9-140

Lewinson, O., and Bibi, E. (2001). Evidence for simultaneous binding of dissimilar substrates by the Escherichia coli multidrug transporter MdfA. Biochemistry 40 12612-12618.

Liassine, N., Madec, S., Ninet, B. Metral, C., Fouchereau-Peron, M. Labia, R., and Auckenthaler, R. (2002). Postneurosurgical meningitis due to Proteus penneri with selection of a ceftriaxone-resistant isolate: analysis of chromosomal class A beta-lactamase HugA and its LysR-type regulatory protein HugR. Antimicrob. Agents Chemother. 46 216-219.

Lister, P. D., Wolter, D. J., and Hanson, N. D. (2009). Antibacterialresistant Pseudomonas aeruginosa: clinical impact and complex regulation of chromosomally encoded resistance mechanisms. Clin. Microbiol. Rev. 22, 582-610.

Lu, S. Y., Zhang, Y. L., Geng, S. N., Li, T. Y., Ye, Z. M., Zhang, D. S., Zou, F., and Zhou, H. W. (2010). High diversity of extendedspectrum beta-lactamase-producing bacteria in an urban river sediment habitat. Appl. Environ. Microbiol. 76, 5972-5976.

Luczkiewicz, A., Jankowska, K., Kurlenda, J., and OlanczukNeyman, K. (2010). Identification and antimicrobial resistance of Enterococcus spp. isolated from surface water. Water Sci. Technol. 62, 466-473.

Martinez, J. L. (2009). Environmental pollution by antibiotics and by antibiotic resistance determinants. Environ. Pollut. 157, 2893-2902.

Martinez, J. L., Sanchez, M. B., Martinez-Solano, L., Hernandez, A. Garmendia, L., Fajardo, A., and Alvarez-Ortega, C. (2009). Functional role of bacterial multidrug efflux pumps in microbial natural ecosystems. FEMS Microbiol. Rev. 33, 430-449.

Mataseje, L. F., Neumann, N., Crago, B., Baudry, P., Zhanel, G. G., Louie, M., and Mulvey, M. R. (2009). Characterization of cefoxitin-resistant Escherichia coli isolates from recreational beaches and private drinking water in Canada between 2004 and 2006. Antimicrob. Agents Chemother. 53, 3126-3130.

Meibom, K. L., Blokesch, M., Dolganov, N. A., Wu, C. Y., and Schoolnik, G. K. (2005). Chitin induces natural competence in Vibrio cholerae. Science 310, 1824-1827.

Michon, A., Allou, N., Chau, F., Podglajen, I., Fantin, B., and Cambau, E. (2011). Plasmidic qnrA3 enhances Escherichia coli fitness in absence of antibiotic exposure. PLoS ONE 6, e24552. doi:10.1371/journal.pone.0024552

Moken, M. C., Mcmurry, L. M., and Levy, S. B. (1997). Selection of multiple-antibiotic-resistant (mar) mutants of Escherichia coli by using the disinfectant pine oil: roles of the mar and acrAB loci. Antimicrob. Agents Chemother. 41, 2770-2772.

Molin, S., and Tolker-Nielsen, T. (2003). Gene transfer occurs with enhanced efficiency in biofilms and induces enhanced stabilisation of the biofilm structure. Curr. Opin. Biotechnol. 14 255-261.

Mosqueda, G., and Ramos, J. L. (2000). A set of genes encoding a second toluene efflux system in Pseudomonas putida DOT$\mathrm{T} 1 \mathrm{E}$ is linked to the tod genes for toluene metabolism. J. Bacteriol. 182, 937-943.

Naas, T., Cuzon, G., Villegas, M. V., Lartigue, M. F., Quinn, J. P., and Nordmann, P. (2008). Genetic structures at the origin of acquisition of the beta-lactamase $b l a_{\mathrm{KPC}}$ gene. 
Antimicrob. Agents Chemother. 52, 1257-1263.

Naas, T., and Nordmann, P. (1994). Analysis of a carbapenemhydrolyzing class A beta-lactamase from Enterobacter cloacae and of its LysR-type regulatory protein. Proc. Natl. Acad. Sci. U.S.A. 91, 7693-7697.

Nikaido, H., and Pages, J. M. (2011). Broad-specificity efflux pumps and their role in multidrug resistance of Gram-negative bacteria. FEMS Microbiol. Rev. doi: 10.1111/j.15746976.2011.00290.x

Parsley, L. C., Consuegra, E. J., Kakirde, K. S., Land, A. M., Harper, W. F. Jr., and Liles, M. R. (2010). Identification of diverse antimicrobial resistance determinants carried on bacterial, plasmid, or viral metagenomes from an activated sludge microbial assemblage. Appl. Environ. Microbiol. 76, 3753-3757.

Peduzzi, J., Farzaneh, S., Reynaud, A., Barthelemy, M., and Labia, R. (1997). Characterization and amino acid sequence analysis of a new oxyimino cephalosporin-hydrolyzing class A beta-lactamase from Serratia fonticola CUV. Biochim. Biophys. Acta 1341, 58-70.

Peduzzi, J., Reynaud, A., Baron, P., Barthelemy, M., and Labia, R. (1994). Chromosomally encoded cephalosporin-hydrolyzing betalactamase of Proteus vulgaris RO104 belongs to Ambler's class A. Biochim. Biophys. Acta 1207, 31-39.

Pei, R., Kim, S. C., Carlson, K. H., and Pruden, A. (2006). Effect of river landscape on the sediment concentrations of antibiotics and corresponding antibiotic resistance genes (ARG). Water Res. 40, 2427-2435.

Pellegrini, C., Mercuri, P. S., Celenza, G., Galleni, M., Segatore, B., Sacchetti, E., Volpe, R., Amicosante, G., and Perilli, M. (2009). Identification of bla $a_{\mathrm{IMP}-22}$ in Pseudomonas spp. in urban wastewater and nosocomial environments: biochemical characterization of a new IMP metalloenzyme variant and its genetic location. J. Antimicrob. Chemother. 63, 901-908.

Pérez-Parada, A., Aguera, A., GomezRamos Mdel, M., Garcia-Reyes, J. F., Heinzen, H., and FernandezAlba, A. R. (2011). Behavior of amoxicillin in wastewater and river water: identification of its main transformation products by liquid chromatography/electrospray quadrupole time-of-flight mass spectrometry. Rapid Commun. Mass Spectrom. 25, 731-742.
Perichon, B., Courvalin, P., and Galimand, M. (2007). Transferable resistance to aminoglycosides by methylation of G1405 in 16S rRNA and to hydrophilic fluoroquinolones by QepA-mediated efflux in Escherichia coli. Antimicrob. Agents Chemother. 51, 2464-2469.

Perilli, M., Franceschini, N., Segatore, B., Amicosante, G., Oratore, A., Duez, C., Joris, B., and Frere, J. M. (1991). Cloning and nucleotide sequencing of the gene encoding the betalactamase from Citrobacter diversus. FEMS Microbiol. Lett. 67, 79-84.

Petkovic, H., Cullum, J., Hranueli, D., Hunter, I. S., Peric-Concha, N. Pigac, J., Thamchaipenet, A., Vujaklija, D., and Long, P. F. (2006). Genetics of Streptomyces rimosus, the oxytetracycline producer. Microbiol. Mol. Biol. Rev. 70, 704-728.

Picao, R. C., Poirel, L., Demarta, A., Silva, C. S., Corvaglia, A. R., Petrini, O., and Nordmann, P. (2008). Plasmid-mediated quinolone resistance in Aeromonas allosaccharophila recovered from a Swiss lake. J. Antimicrob. Chemother. 62, 948-950.

Piddock, L. J. (2006). Multidrugresistance efflux pumps - not just for resistance. Nat. Rev. Microbiol. 4, 629-636.

Pitout, J. D., Nordmann, P., Laupland, K. B., and Poirel, L. (2005). Emergence of Enterobacteriaceae producing extended-spectrum betalactamases (ESBLs) in the community. J. Antimicrob. Chemother. 56, 52-59.

Poirel, L., Figueiredo, S., Cattoir, V., Carattoli, A., and Nordmann, P. (2008). Acinetobacter radioresistens as a silent source of carbapenem resistance for Acinetobacter spp. Antimicrob. Agents Chemother. 52, 1252-1256.

Poirel, L., Heritier, C., and Nordmann, P. (2004). Chromosomeencoded ambler class $\mathrm{D}$ betalactamase of Shewanella oneidensis as a progenitor of carbapenemhydrolyzing oxacillinase. Antimicrob. Agents Chemother. 48, 348-351.

Poirel, L., Kampfer, P., and Nordmann, P. (2002). Chromosome-encoded Ambler class A beta-lactamase of Kluyvera georgiana, a probable progenitor of a subgroup of CTX-M extended-spectrum beta-lactamases. Antimicrob. Agents Chemother. 46, 4038-4040.

Poirel, L., Liard, A., RodriguezMartinez, J. M., and Nordmann, P. (2005a). Vibrionaceae as a possible source of Qnr-like quinolone resistance determinants. J. Antimicrob. Chemother. 56, 1118-1121.
Poirel, L., Rodriguez-Martinez, J. M., Mammeri, H., Liard, A., and Nordmann, P. (2005b). Origin of plasmid-mediated quinolone resistance determinant QnrA. Antimicrob. Agents Chemother. 49, 3523-3525.

Poirel, L., Naas, T., and Nordmann, P. (2010). Diversity, epidemiology, and genetics of class D beta-lactamases. Antimicrob. Agents Chemother. 54, 24-38.

Poole, K. (2004). Efflux-mediated multiresistance in Gram-negative bacteria. Clin. Microbiol. Infect. 10, 12-26.

Potron, A., Poirel, L., Bussy, F., and Nordmann, P. (2011). Occurrence of the carbapenem-hydrolyzing beta-lactamase gene bla $a_{\text {OXA- } 48}$ in the environment in Morocco. Antimicrob. Agents Chemother. 55, 5413-5414.

Queenan, A. M., and Bush, K. (2007). Carbapenemases: the versatile betalactamases. Clin. Microbiol. Rev. 20, 440-458.

Quinteira, S., Ferreira, H., and Peixe, L. (2005). First isolation of bla $a_{\mathrm{VIM}-2}$ in an environmental isolate of Pseudomonas pseudoalcaligenes. Antimicrob. Agents Chemother. 49, 2140-2141.

Rahmati, S., Yang, S., Davidson, A. L., and Zechiedrich, E. L. (2002). Control of the AcrAB multidrug efflux pump by quorum-sensing regulator SdiA. Mol. Microbiol. 43, 677-685.

Randall, L. P., Clouting, C., Horton, R. A., Coldham, N. G., Wu, G., CliftonHadley, F. A., Davies, R. H., and Teale, C. J. (2011). Prevalence of Escherichia coli carrying extendedspectrum beta-lactamases (CTX-M and TEM-52) from broiler chickens and turkeys in Great Britain between 2006 and 2009. J. Antimicrob. Chemother. 66, 86-95.

Ripp, S., and Miller, R. V. (1995). Effects of suspended particulates on the frequency of transduction among Pseudomonas aeruginosa in a freshwater environment. Appl. Environ. Microbiol. 61, 1214-1219.

Rodriguez, M. M., Power, P., Radice, M., Vay, C., Famiglietti, A., Galleni, M., Ayala, J. A., and Gutkind, G. (2004). Chromosome-encoded CTX-M-3 from Kluyvera ascorbata: a possible origin of plasmid-borne CTX-M-1-derived cefotaximases. Antimicrob. Agents Chemother. 48, 4895-4897.

Rodriguez-Martinez, J. M., Cano, M. E., Velasco, C., Martinez-Martinez, L., and Pascual, A. (2011). Plasmidmediated quinolone resistance: an update. J. Infect. Chemother. 17, 149-182.
Rossolini, G. M. (2005). Acquired metallo-beta-lactamases: an increasing clinical threat. Clin. Infect. Dis. 41, 1557-1558.

Sánchez, M. B., Hernandez, A., Rodriguez-Martinez, J. M. Martinez-Martinez, L., and Martinez, J. L. (2008). Predictive analysis of transmissible quinolone resistance indicates Stenotrophomonas maltophilia as a potential source of a novel family of Qnr determinants. BMC Microbiol. 8, 148 doi:10.1186/1471-2180-8-148

Sanchez, P., Linares, J. F., Ruiz-Diez, B., Campanario, E., Navas, A., Baquero, F., and Martinez, J. L. (2002). Fitness of in vitro selected Pseudomonas aeruginosa nal $\mathrm{B}$ and $n f x \mathrm{~B}$ multidrug resistant mutants. J. Antimicrob. Chemother. 50, 657-664.

Sandegren, L., and Andersson, D. I. (2009). Bacterial gene amplification: implications for the evolution of antibiotic resistance. Nat. Rev. Microbiol. 7, 578-588.

Schwartz, T., Kohnen, W., Jansen, B., and Obst, U. (2003). Detection of antibiotic-resistant bacteria and their resistance genes in wastewater, surface water, and drinking water biofilms. FEMS Microbiol. Ecol. 43, 325-335.

Schwartz, T., Volkmann, H., Kirchen, S., Kohnen, W., Schon-Holz, K., Jansen, B., and Obst, U. (2006). Realtime PCR detection of Pseudomonas aeruginosa in clinical and municipal wastewater and genotyping of the ciprofloxacin-resistant isolates. FEMS Microbiol. Ecol. 57, 158-167.

Scotta, C., Juan, C., Cabot, G., Oliver, A., Lalucat, J., Bennasar A., and Alberti, S. (2011). Environmental microbiota represents a natural reservoir for dissemination of clinically relevant metallobeta-lactamases. Antimicrob. Agents Chemother. 55, 5376-5379.

Sengelov, G., and Sorensen, S. J. (1998). Methods for detection of conjugative plasmid transfer in aquatic environments. Curr. Microbiol. 37, 274-280.

Seoane, A., and Garcia Lobo, J. M. (1991). Nucleotide sequence of a new class A beta-lactamase gene from the chromosome of Yersinia enterocolitica: implications for the evolution of class A beta-lactamases. Mol. Gen. Genet. 228, 215-220.

Silver, S., and Phung, L. T. (1996). Bacterial heavy metal resistance: new surprises. Annu. Rev. Microbiol. 50, 753-789.

Sosa, V., Schlapp, G., and Zunino, P. (2006). Proteus mirabilis isolates of 
different origins do not show correlation with virulence attributes and can colonize the urinary tract of mice. Microbiology 152, 2149-2157.

Srinivasiah, S., Bhavsar, J., Thapar, K., Liles, M., Schoenfeld, T., and Wommack, K. E. (2008). Phages across the biosphere: contrasts of viruses in soil and aquatic environments. Res. Microbiol. 159, 349-357.

Talebi, M., Pourshafie, M. R., Katouli, M., and Mollby, R. (2008). Molecular structure and transferability of Tn1546-like elements in Enterococcus faecium isolates from clinical, sewage, and surface water samples in Iran. Appl. Environ. Microbiol. 74, 1350-1356.

Taylor, N. G., Verner-Jeffreys, D. W., and Baker-Austin, C. (2011). Aquatic systems: maintaining, mixing and mobilising antimicrobial resistance? Trends Ecol. Evol. (Amst.) 26, 278-284.

Teitzel, G. M., Geddie, A., De Long, S. K., Kirisits, M. J., Whiteley, M., and Parsek, M. R. (2006). Survival and growth in the presence of elevated copper: transcriptional profiling of copper-stressed Pseudomonas aeruginosa. J. Bacteriol. 188, 7242-7256.

Toleman, M. A., Bennett, P. M., and Walsh, T. R. (2006). Common regions e.g. orf513 and antibiotic resistance: IS91-like elements evolving complex class 1 integrons. J. Antimicrob. Chemother. 58, 1-6.

Tsubakishita, S., Kuwahara-Arai, K., Sasaki, T., and Hiramatsu, K. (2010). Origin and molecular evolution of the determinant of methicillin resistance in staphylococci. Antimicrob. Agents Chemother. 54, 4352-4359.

Velasco, C., Rodriguez-Martinez, J. M., Briales, A., Diaz De Alba, P., Calvo, J., and Pascual, A. (2010). Smaqnr, a new chromosome-encoded quinolone resistance determinant in Serratia marcescens. J. Antimicrob. Chemother. 65, 239-242.

Vimont, S., Poirel, L., Naas, T., and Nordmann, P. (2002). Identification of a chromosome-borne expanded-spectrum class a betalactamase from Erwinia persicina. Antimicrob. Agents Chemother. 46, 3401-3405.

Walckenaer, E., Poirel, L., LeflonGuibout, V., Nordmann, P., and Nicolas-Chanoine, M. H. (2004). Genetic and biochemical characterization of the chromosomal class A beta-lactamases of Raoultella (formerly Klebsiella) planticola and Raoultella ornithinolytica. Antimicrob. Agents Chemother. 48, 305-312.

Walsh, T. R., Weeks, J., Livermore, D. M., and Toleman, M. A. (2011). Dissemination of NDM-1 positive bacteria in the New Delhi environment and its implications for human health: an environmental point prevalence study. Lancet Infect. Dis. 11, 355-362.

Weinbauer, M. G. (2004). Ecology of prokaryotic viruses. FEMS Microbiol. Rev. 28, 127-181.

Wiedenbeck, J., and Cohan, F. M. (2011). Origins of bacterial diversity through horizontal genetic transfer and adaptation to new ecological niches. FEMS Microbiol. Rev. 35, 957-976.
Wright, G. D. (2010). Antibiotic resistance in the environment: a link to the clinic? Curr. Opin. Microbiol. 13, 589-594.

Wright, M. S., Baker-Austin, C., Lindell, A. H., Stepanauskas, R., Stokes, H. W., and Mcarthur, J. V. (2008). Influence of industrial contamination on mobile genetic elements: class 1 integron abundance and gene cassette structure in aquatic bacterial communities. ISME J. 2, 417-428.

Xia, R., Guo, X., Zhang, Y., and Xu, H. (2010). qnrVC-like gene located in a novel complex class 1 integron harboring the ISCR1 element in an Aeromonas punctato strain from an aquatic environment in Shandong Province, China. Antimicrob. Agents Chemother. 54, 3471-3474.

Yang, J. F., Ying, G. G., Zhao, J. L., Tao R., Su, H. C., and Liu, Y. S. (2011) Spatial and seasonal distribution of selected antibiotics in surface waters of the Pearl Rivers, China. J. Environ. Sci. Health B 46, 272-280.

Yigit, H., Queenan, A. M., Anderson, G. J., Domenech-Sanchez, A., Biddle, J. W., Steward, C. D., Alberti, S., Bush, K., and Tenover, F. C. (2001). Novel carbapenemhydrolyzing beta-lactamase, KPC1, from a carbapenem-resistant strain of Klebsiella pneumoniae. Antimicrob. Agents Chemother. 45, 1151-1161.

Zhang, Q., Lambert, G., Liao, D. Kim, H., Robin, K., Tung, C. K., Pourmand, N., and Austin, R. H. (2011). Acceleration of emergence of bacterial antibiotic resistance in connected microenvironments. Science 333, 1764-1767.

Zhao, J., Chen, Z., Chen, S., Deng, Y., Liu, Y., Tian, W., Huang, X., Wu, C., Sun, Y., Zeng, Z., and Liu, J. H. (2010). Prevalence and dissemination of oqx $\mathrm{AB}$ in Escherichia coli isolates from animals, farmworkers, and the environment. Antimicrob. Agents Chemother. 54, 4219-4224.

Conflict of Interest Statement: The authors declare that the research was conducted in the absence of any commercial or financial relationships that could be construed as a potential conflict of interest.

Received: 10 November 2011; paper pending published: 05 December 2011; accepted: 10 January 2012; published online: 26 January 2012.

Citation: Lupo A, Coyne $S$ and Berendonk TU (2012) Origin and evolution of antibiotic resistance: the common mechanisms of emergence and spread in water bodies. Front. Microbio. 3:18. doi: 10.3389/fmicb.2012.00018

This article was submitted to Frontiers in Antimicrobials, Resistance and Chemotherapy, a specialty of Frontiers in Microbiology.

Copyright (C) 2012 Lupo, Coyne and Berendonk. This is an open-access article distributed under the terms of the Creative Commons Attribution Non Commercial License, which permits noncommercial use, distribution, and reproduction in other forums, provided the original authors and source are credited. 